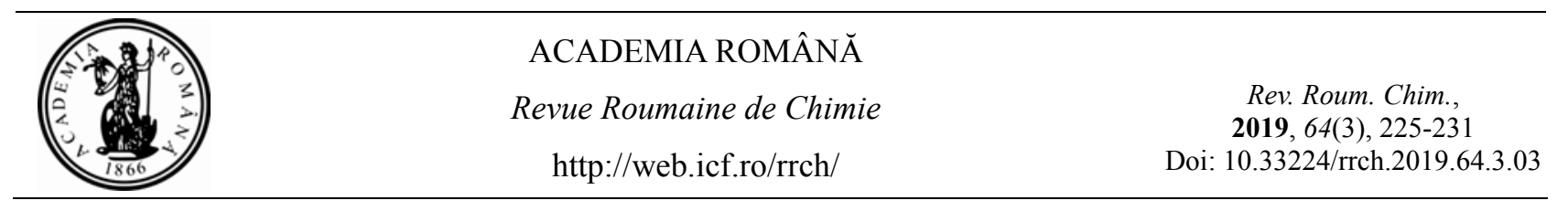

\title{
STUDY ON MICROPHASE SEPARATION OF NOVEL CROSSLINKED POLYURETHANE BY AFM AND DMA
}

\author{
Xiangqian FAN, Zhiping $\mathrm{LV}^{*}$ and Xiang ZU \\ College of Chemistry and Chemical Engineering, Taiyuan University of Technology, Taiyuan 030024, China
}

Received November 6, 2017

A series of novel crosslinked PU composites were synthesized using polytetramethylene (PTMG), toluene diisocyanate (TDI), 3,5-dimethylthiotoluenediamine (DAMTDA, E-300) as raw materials, and glycine-calcium bromide (GCB) semi-organic crystal and GCB-crystal mixed $\mathrm{SiO}_{2}$ or $13 \mathrm{X}$-zeolite respectively as modifier by a prepolymer method. The macroscopic property and microstructure were characterized by mechanical tests, atomic force microscopy (AFM) analysis and dynamic mechanical analysis (DMA). The results showed that effects of different composite particles on the microphase separation of novel crosslinked PU composites were different. The extent of the microphase separation of PU composites was showed by AFM analysis visually. And the results of DMA not only gave the information about energy storage modulus, energy dissipation modulus and the microphase separation of PU composites, but also reflected the interaction between the macromolecular chains and nanoparticles preferably.
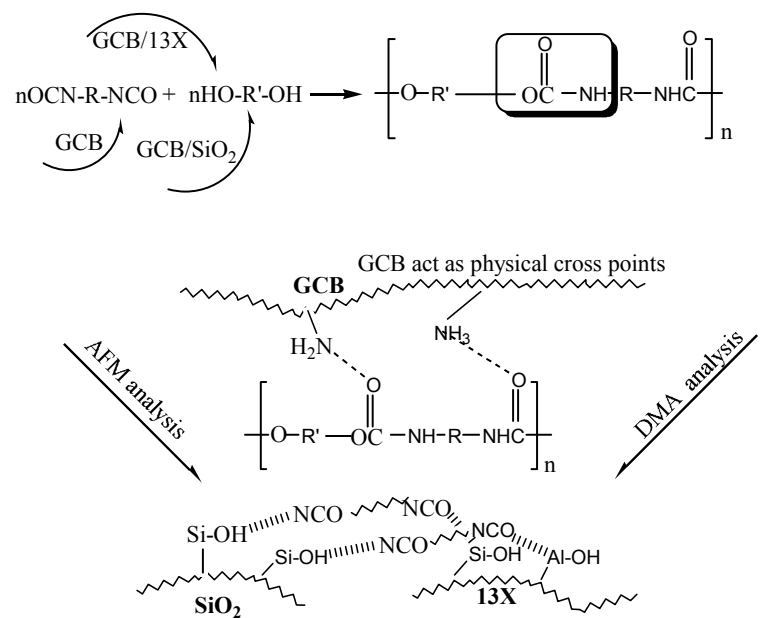

\section{INTRODUCTION}

Thermoplastic polyurethane are composed of soft segments and hard segments arranged alternately and microphase separation is the most prominent characteristic of polyurethane. ${ }^{1-5}$ The excellent physical and chemical properties of PU are highly dependent on microphase separation which are generally attribute to chemical incompatibility between the hard and soft segments, in which hard segments tends to form a hard microregion by self-aggregation. ${ }^{6-11}$ However, microphase separation is usually incomplete and some hard segments may be scattered or embedded into soft segments to form an interface region. ${ }^{12-14}$

The relationship between microphase separation and properties of polyurethane has been studied extensively. X. Wang et al. ${ }^{15}$ studied the microstructures of FPUs and H-bond interactions focusing on the influences of fluorine (F) content on the separation between the soft and hard phases by combining experimental and computational approaches. L. Rueda et al. ${ }^{16}$ analyzed the biodegradability of polyurethane from the viewpoint of microdomains structure by DSC and ATR-IR. S. L. $\mathrm{Wu}$ et $a .^{17}$ investigated the effects of aminefunctionalized reduced graphene oxide $\left(\mathrm{NH}_{2}-\right.$ $\mathrm{RGO}$ ) on the microphase structure and mechanical and thermal properties of $\mathrm{NH}_{2}-\mathrm{RGO} / \mathrm{WPU}$ nanocomposites.

There are many methods to investigate the microphase separation of PU, such as FTIR, DSC, SEM, DMA, and AFM and so on. However, test sample preparation is difficult and results are not

\footnotetext{
*Corresponding author: lzping8138@163.com
} 
intuitive using FTIR and $\mathrm{DSC},{ }^{18}$ calculation parameters are complicated and experimental conditions are harsh for many researchers using thermodynamic factors (such as Gibbs free energy $\Delta \mathrm{G}_{\mathrm{m}}$ or Flory-Huggins interaction parameter, $\left.\chi\right)^{19}$ In contrast, these drawbacks can be avoided by DMA and AFM analysis. On the one hand, testsample preparation is simple during the characterization compared with other methods, on the other hand, the characterization results are visualized and informative. ${ }^{20,21}$ Organic-inorganic hybrid composites have attracted much interest in materials science as they often exhibit particular properties. ${ }^{22,23}$ GCB-crystal is a kind of semiorganic crystal with a special surface, which may strongly affect the macroscopic behavior and microphase separation or crystallization between the soft and hard segments of polyurethane composites. However, to the best of our knowledge, there have been no attempts to exploit the interaction between GCB-crystal and polyurethane (PU). Therefore, in this paper, glycine-calcium bromide (GCB) semi-organic crystal $\left(\left[\mathrm{CaBr}_{2}\left(\mathrm{NH}_{3}{ }^{+} \mathrm{CH}_{2} \mathrm{COO}^{-}\right)_{2}\right] \cdot 4 \mathrm{H}_{2} \mathrm{O}\right)$, GCBcrystal $/ \mathrm{SiO}_{2}$ and GCB-crystal/13X-zeolite mixed particles were used as modifier to improve the microphase separation of PU composites, at the same time, the effects of different particles on microphase structure and comprehensive properties of PU composites were characterized using AFM and DMA.

\section{EXPERIMENTAL}

\section{Materials}

Poly(oxytetramethylene) glycol (PTMG: $\mathrm{M}_{\mathrm{n}}=2000$, Mitsui Chemicals Inc\& Co), 2,4-toluene diisocyanate (Bayer, Germany), dimethythiotoluene diamine (DMTDA, E-300, Dafeng tiancheng chemical co. LTD), glycine (commie chemical reagent co. LTD, Tianjin), calcium bromide ( $\mathrm{CaBr}_{2}$, Guangfu fine chemical research institute, Tianjin), $\mathrm{SiO}_{2}$, (shengpu information technology development co. LTD, Shanghai), 13X- Zeolite (particle diameter is about $20-30 \mathrm{~nm}$, Coda molecular sieve co. LTD, Dalian).

\section{Preparation of GCB semi-organic crystal}

Glycine-calcium bromide (GCB) semi-organic crystal was synthesized by solvent evaporation method from aqueous solution. The solubility of glycine was proportional to the temperature, so super-saturated solution of glycine were obtained by dissolving glycine in double distilled water at $60^{\circ} \mathrm{C}$ in a constant temperature bath before cooling to $50^{\circ} \mathrm{C}$ slowly. Then calcium dibromide was added to glycine supersaturated solution in the stoichiometric ratio $2: 1$ with continuous stirring. ${ }^{24}$

$$
\begin{aligned}
& 2 \mathrm{NH}_{2} \mathrm{CH}_{2} \mathrm{COOH}+\mathrm{CaBr}_{2}+4 \mathrm{H}_{2} \mathrm{O} \rightarrow \\
& \rightarrow\left[\mathrm{CaBr}_{2}\left(\mathrm{NH}_{3}{ }^{+} \mathrm{CH}_{2} \mathrm{COO}^{-}\right)_{2}\right] \cdot 4 \mathrm{H}_{2} \mathrm{O}
\end{aligned}
$$

The solution was filtered and filtrate was kept undisturbed in a clear beaker without the effect of impurity and dust, GCB semi-organic crystal were obtained by slow evaporation under above condition. Then GCB semi-organic crystal were dried at $100^{\circ} \mathrm{C}$ in oven and grinded to $20-30 \mathrm{~nm}$.

\section{Preparation of prepolymer}

GCB semi-organic crystal alone or together with $\mathrm{SiO}_{2}$ and 13X-zeolite were poured into the grinder respectively and mixed uniformly after grinding three times repeatedly. The aforesaid mixed particles and PTMG were decanted into a four-necked round-bottom flask of $1000 \mathrm{~mL}$ equipped with a thermometer and a mechanical stirrer, then the mixture were dehydrated for $2 \mathrm{~h}$ when the pressure of system was pumped to $-0.09 \mathrm{Mpa}$ gradually and the temperature was elevated from room temperature to $110^{\circ} \mathrm{C}$. Besides, TDI (the preset value of $-\mathrm{NCO} \%$ was $5.4 \%$ in prepolymer) was added to the reaction vessel when the temperature was dropped to $40^{\circ} \mathrm{C}$ and stirred for $30 \mathrm{~min}$, then the stirring sustained $2 \mathrm{~h}$ at $80^{\circ} \mathrm{C}$ under a nitrogen atmosphere. The content of -NCO were analyzed and the reaction was finished while the results of the analysis were as the same as the preset value. Desired prepolymer were obtained after removing the involved air in vacuum at $60^{\circ} \mathrm{C}$ for $30 \mathrm{~min}$.

\section{Preparation of $P U$ composites}

The prepolymer was heated up to $80^{\circ} \mathrm{C}$ and defoamed, then quantitative chain extender of E-300 was added to prepolymer and defoamed again after stirring 30 s quickly. The viscous liquids were poured into preheating-mold and moved in plate vulcanizing machine to vulcanize for $20 \mathrm{~min}$ at $120^{\circ} \mathrm{C}$, the products of PU composites films (Table 1) were vulcanized again in drying oven for $24 \mathrm{~h}$ at $100^{\circ} \mathrm{C}$, and then, they were conducted a serious of tests after storing at room temperature for a week.

\section{Characterization}

Mechanical testing was performed with a tensile testing machine at $25^{\circ} \mathrm{C}$. The test samples of the tensile strength and tear-resistance strength can be prepared in the form of dumbbell-shaped and rectangular-shaped simply using standard cutter according to GB/T 528-2009 and GB/T 5292008 , respectively. The tensile speed was $500 \mathrm{~mm} / \mathrm{min}$.

Table 1

PU samples and composition

\begin{tabular}{cc}
\hline Sample & Composition \\
\hline PU-0 & Pure PU \\
PU-1 & PU/1\%GCB-crystal \\
PU-2 & PU $/ 1 \%$ GCB-crystal $+0.5 \% \mathrm{SiO}_{2}$ \\
PU-3 & PU $/ 1 \%$ GCB-crystal $+1.0 \% 13 \mathrm{X}$ \\
\hline
\end{tabular}


To conduct the AFM scanning, the test samples were cut into a piece of film with a size of $5 \mathrm{~mm} \times 5 \mathrm{~mm}$ and were pasted on a mica sheet before scanning. Then AFM analysis of the test samples was done using a commercial AFM system (NTEGRA Solaris, Russia NT-MDI co. LTD) and Nanoscope Analysis version 1.40 (Bruker Corporation).

Dynamic mechanical properties were measured with a DMA-Q800 (TA instruments, USA). The preparation process of the test-sample was facile, just need to tailor the sample elongated with a length of $30 \mathrm{~mm}$, a width of $8 \mathrm{~mm}$, and a thickness of $2 \mathrm{~mm}$. Then the measurements were performed in the temperature range from $-80^{\circ} \mathrm{C}$ to $100^{\circ} \mathrm{C}$ with a constant frequency of $1 \mathrm{~Hz}$ and a heating rate of $5^{\circ} \mathrm{C} / \mathrm{min}$ in a nitrogen atmosphere.

\section{RESULTS AND DISCUSSION}

\section{Mechanical testing}

The tear-resistance strength and tensile strength of pure $\mathrm{PU}$ and $\mathrm{PU}$ composites are showed in Figure 1, in which $\mathrm{f}\left(\mathrm{f}=\mathrm{n}\left(-\mathrm{NH}_{2}\right) / \mathrm{n}(-\mathrm{NCO})\right)$ represents chain extension coefficient. Mechanical properties of each sample were tested under four different chain extension coefficients.

As shown in Figure 1, the tear-resistance strength and tensile strength of PU composites are higher than that of pure PU. The improved mechanical properties of PU composites have a direct relationship with the inside micromorphology and the possible reason can be account as follows.

The hydrogenation and crystallization of hard segments are increased due to the interaction between GCB-crystal and hard segments, besides GCB-crystal act as physical interconnection points and hard segments gathered around GCB-crystal, which increase the rigidity of PU composites. As a result, the mechanical performances of PU composites are improved. The network structure or short-chain polyurethane is formed by reaction between TDI and $\mathrm{Si}-\mathrm{OH}$ in surface of $\mathrm{SiO}_{2}$ or $\mathrm{Si}-\mathrm{OH}$ (or $\mathrm{Al}-\mathrm{OH}$ ) in surface of 13X-zeolite, which increases the crosslinking network of PU composites. At the same time, the unique microporous structure of $13 \mathrm{X}$-zeolite can reduce the bubbles in prepolymer, so as to reduce the appearance of micropores in PU composite materials, consequently, mechanical properties of PU composites are improved accordingly.

\section{Atomic force microscopy (AFM) analysis}

The structure and micromorphology of polymer can be analyzed from nanoscale by Atomic force microscope (AFM) ${ }^{16-21}$ therefore it is intuitive in research of microphase separation by AFM. In this paper, PU composites and pure PU were scanned in the region of $300 \mathrm{~nm} \sim 2 \mu \mathrm{m}$ by AFM.

AFM images of PU composites and pure PU are showed in Figure 2, the dark images representing soft segments and the bright images representing hard segments. ${ }^{25,26}$ The phases of soft and hard segments are distributed alternately, presenting distinct microphase separation.

Figure 2 (a) shows obvious microphase separation of pure PU visually, soft segments present continuous distribution and microcrystal of hard segments are dispersed among soft segments and the size of the crystalline grain is approximately $1 \mathrm{~nm}$. Then the highlight region in PU composites is increased, which indicates that microregion and crystalline grain of hard segments is increased, that is to say, the crystallinity of hard segments is enlarged and microphase separation of PU system is improved accordingly. The three-dimensional (3D) stereogram of pure PU and PU composites are illustrated in Figure 3 to further confirm their microphase separation. The darker domains of soft segments present continuous distribution, while the brighter domains of hard segments present dispersive distribution. ${ }^{27}$ The results are consistent with the $2 \mathrm{D}$ images.
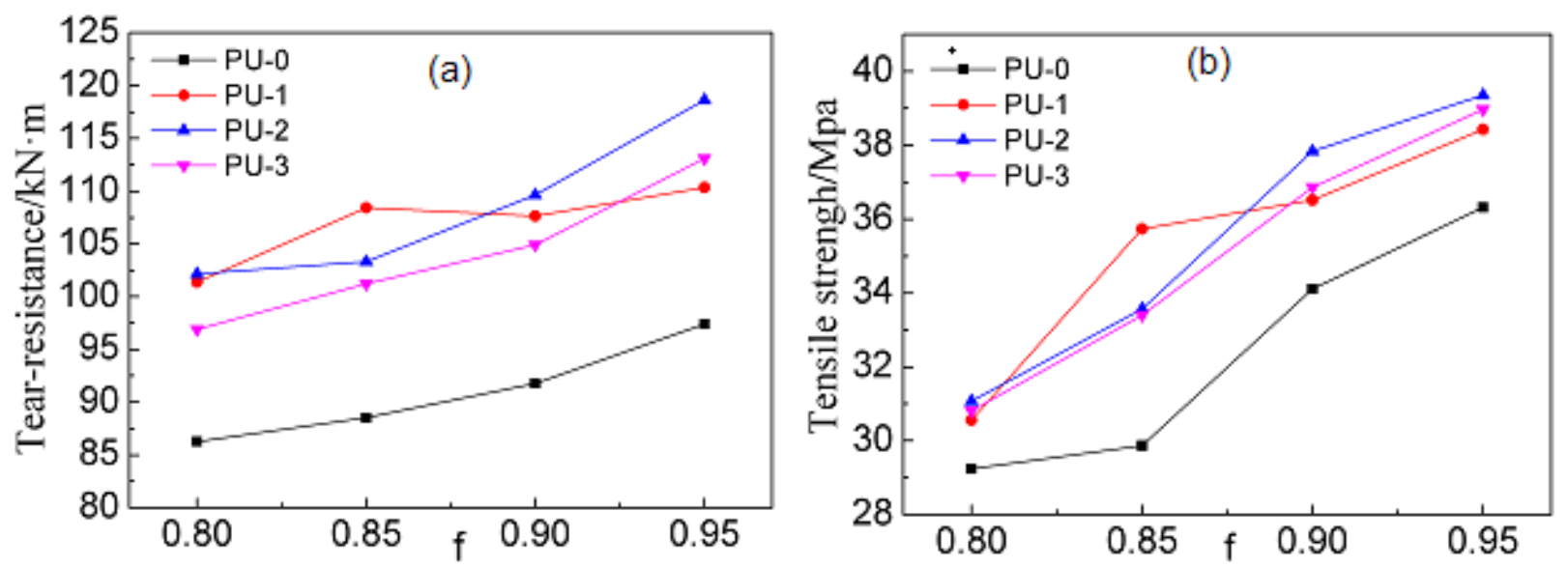

Fig. 1 - Mechanical properties of PU composites: (a) tear-resistance strength; (b) tensile strength. 

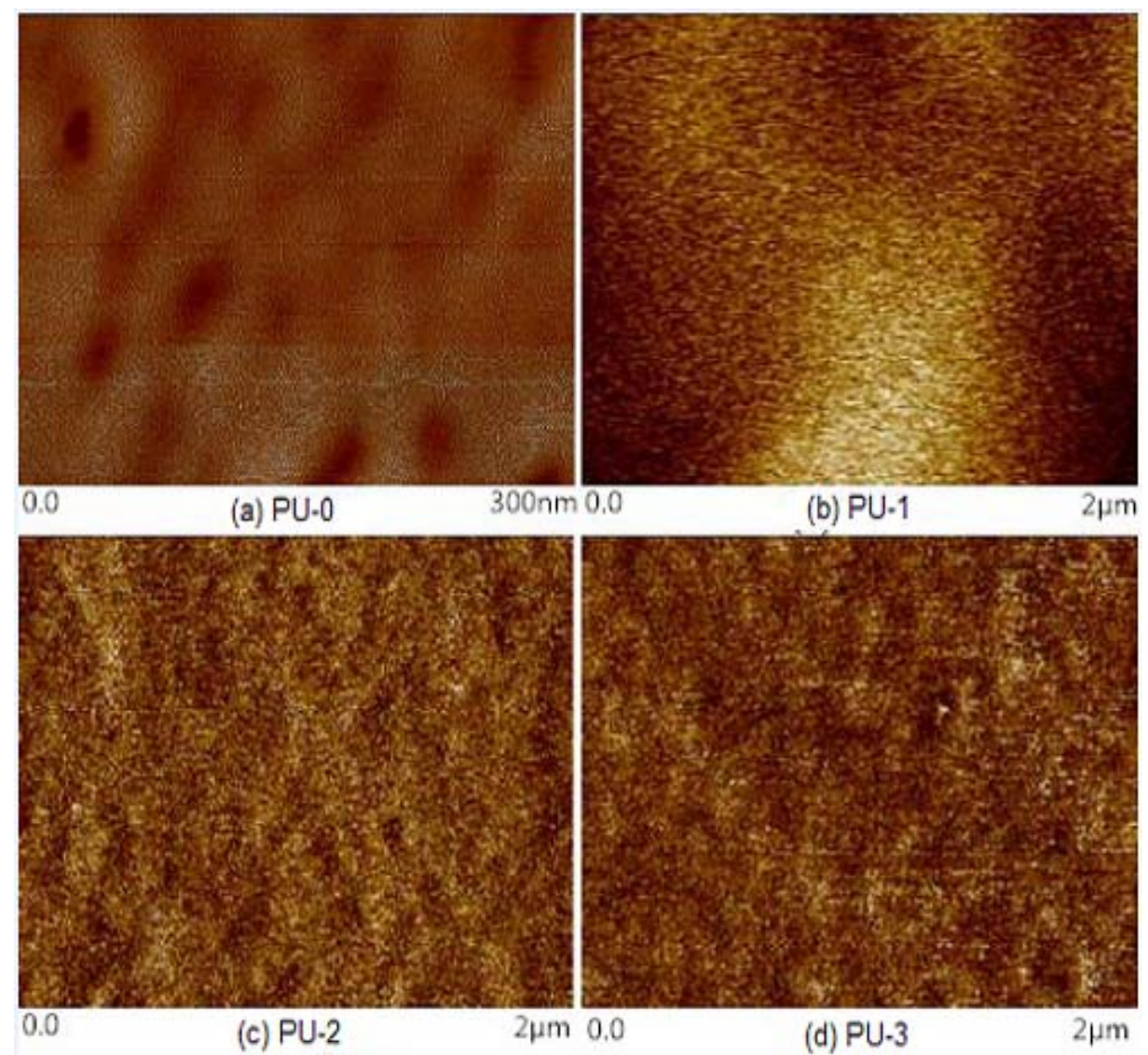

Fig. 2 - AFM 2D images of PU composites.

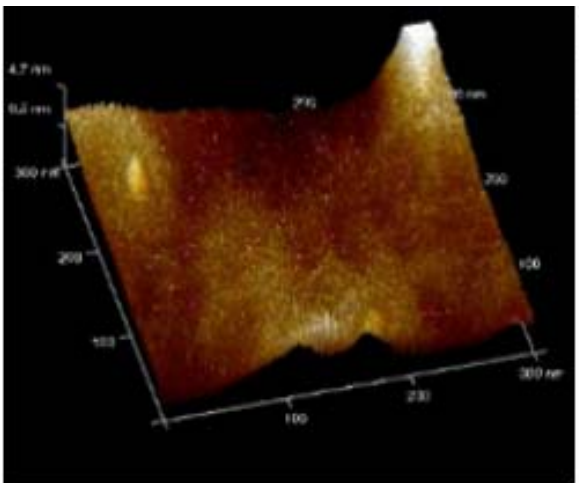

(a) PU-0

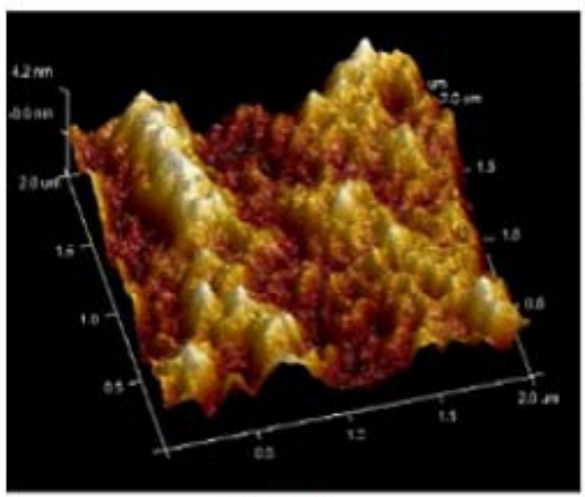

(c) PU-2

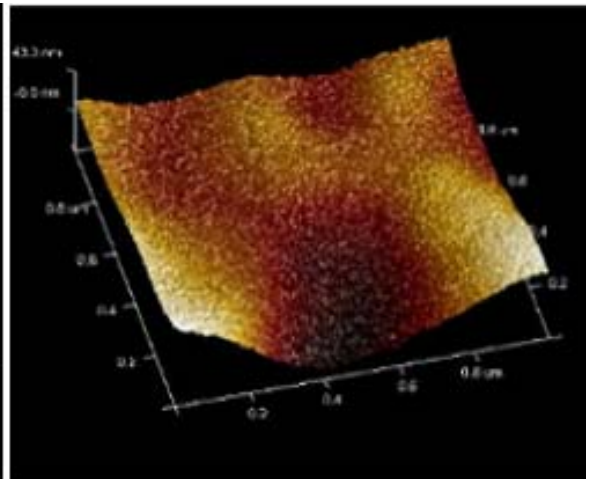

(b) PU-1

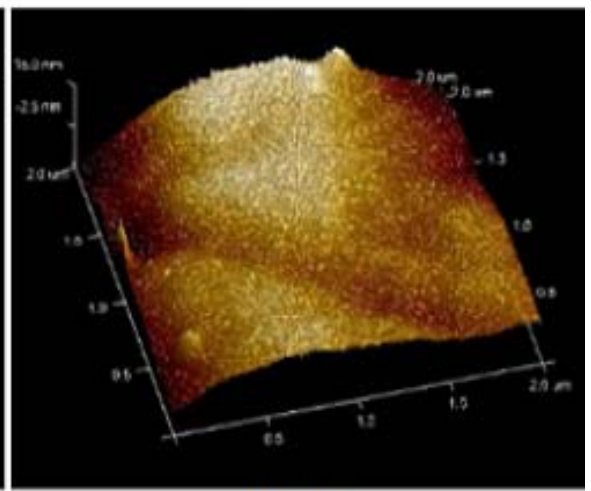

(d) PU-3

Fig. 3 - AFM 3D images of PU composites. 

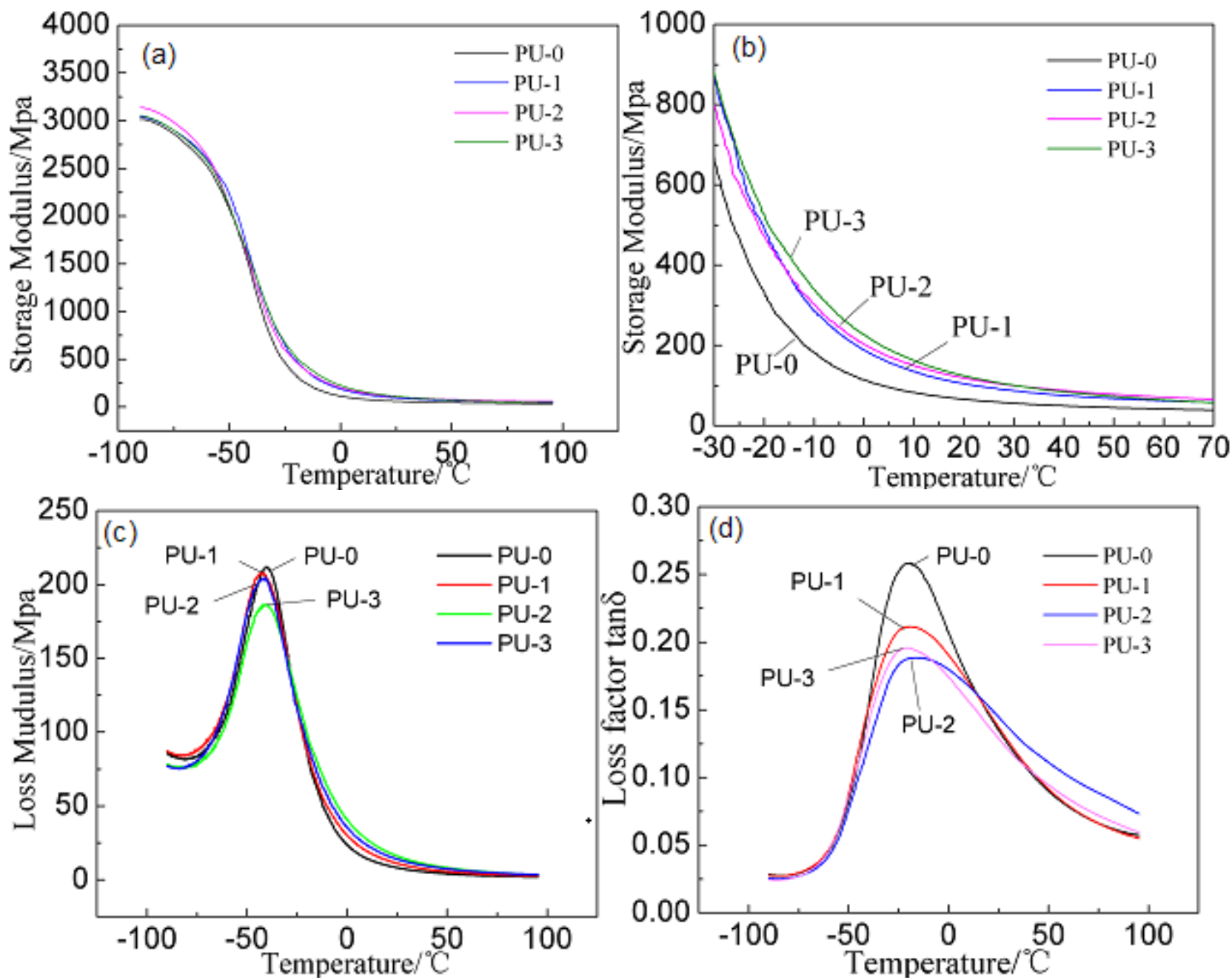

Fig. 4 - DMA curves of PU composites: (a) storage modulus (E') curves; (b) partial amplification of storage modulus (E') curves; (c) consumption modulus $\left(\mathrm{E}^{\prime \prime}\right)$ curves; (d) dissipation factor $(\tan \delta)$ curves.

Table 2

$\mathrm{T}_{\mathrm{g}}$ corresponding to $\mathrm{E}^{\prime \prime}$ and $\tan \delta$

\begin{tabular}{ccccc}
\hline Sample & PU-0 & PU-1 & PU-2 & PU-3 \\
\hline $\mathrm{E}^{\prime \prime}-\mathrm{T}_{\mathrm{g}}\left({ }^{\circ} \mathrm{C}\right)$ & -39.97 & -39.95 & -40.96 & -40.91 \\
$\operatorname{Tan} \delta-\mathrm{T}_{\mathrm{g}}\left({ }^{\circ} \mathrm{C}\right)$ & -19.39 & -19.17 & -18.93 & -20.49 \\
\hline
\end{tabular}

\section{Dynamic mechanical analysis (DMA)}

Dynamic mechanical analysis (DMA) provides a lot of information about polymer, including glass transition temperature $\left(\mathrm{T}_{\mathrm{g}}\right)$, phase separation, modulus and damping performance, ${ }^{28}$ thereby the microphase separation of $\mathrm{PU}$ composites are obtained. DMA measurement was performed to further analysis the microphase separation of PU composites in Figure 4, and the characteristic values are summarized in Table 2.

As illustrated in storage modulus $\left(\mathrm{E}^{\prime}\right)$ curves (Fig. 4 a), $E^{\prime}$ of PU composites are higher than that of pure $\mathrm{PU}$ in normal temperature range, illustrating rigidity and strength of PU composites are higher than that of pure PU. Partial enlarged detail of $E^{\prime} \sim T$ curves at range of $-30 \sim 70^{\circ} \mathrm{C}$ are showed in Figure 4 (b), storage modulus ( $\left.E^{\prime}\right)$ of PU composites still significantly higher than that of pure PU when over normal temperature $\left(60^{\circ} \mathrm{C}\right)$, which declares that heat resistance of $\mathrm{PU}$ are improved obviously after adding particles.

On the one hand, this is due to the formation of hydrogen bonds between $-\mathrm{NH}_{2}$ in GCB-crystal and $-\mathrm{C}=\mathrm{O}$ in hard segments results in the increase of 
crystallization in hard segments, on the other hand, GCB-crystal itself possess high strength, which increases the rigidity of PU composites. Besides, physics or chemistry crosslinking between polyurethane and $\mathrm{Si}-\mathrm{OH}$ in surface of $\mathrm{SiO}_{2}$ can form a three-dimensional network structure and improve the rigidity of PU composites. Therefore, the energy storage modulus of PU composites is improved. The role of Si-OH (or Al-OH) in surface of 13X-zeolite is similar to $\mathrm{SiO}_{2}$.

As demonstrated in Figure 4 (c), the consumption modulus $\left(E^{\prime \prime}\right)$ curves of PU composites are slightly lower than that of pure PU within the whole scope, and maximum of $E^{\prime \prime}\left(E^{\prime \prime}{ }_{\max }\right)$ are also less than that of pure PU. The energy consumed by heat consumption during the experiment is decreased, which indicates that endogenous-heat of PU composites are decreased after adding GCBcrystal, GCB-crystal/ $\mathrm{SiO}_{2}$ or GCB-crystal/13Xzeolite. The corresponding temperature of $\mathrm{E}_{\text {max }}^{\prime \prime}$ represents glass transition temperature $\left(\mathrm{T}_{\mathrm{g}}\right)$. Figure 4 (b) and table 2 show that $\mathrm{T}_{\mathrm{g}}$ of PU composites are slightly lower than $T_{g}$ of pure $P U$, thus the microphase separation of PU composites is better.

The shape and position of $\tan \delta$ peak vary with the compatibility of soft and hard segments, it will shift to low temperature and peak width will narrow when the microphasse separation is better $^{29}$. Shown in Figure 4d, $\tan \delta$ curves of PU composites are below that of pure PU and peak values of $\mathrm{PU}$ composites are lower significantly than that of pure PU. It is suggested that thermal loss of PU composites is less and the microphase separation is better. The corresponding temperature of $\tan \delta$ peak represents $T_{g}$ of soft segments (table 2). $T_{g}$ of PU-3 decreases $1.1^{\circ} \mathrm{C}$ compared with pure PU. There is no much change in PU-1, while $T_{g}$ of PU-2 is slightly higher than that of pure PU and peak width increases slightly. This may because fine particle size and large surface area of $\mathrm{SiO}_{2}$ can enhance the interaction with PU matrix and increase the physical crosslinking network of PU composites. Therefore, it can be seen that DMA analysis is able to reflect the information of interaction between the macromolecular chains and nanoparticles preferably.

\section{CONCLUSION}

In conclusion, we utilized AFM and DMA, two kinds of efficient, quick and intuitive characterization methods, to investigate the microphase separation of crosslinked PU composites. Compared with pure PU, the prepared novel crosslinked PU composites after adding particles with different surface properties can promote microphase separation. AFM phase images not only clearly demonstrate the grain size and shape of hard segments but also reveal its dispersion in soft segments and the microphase separation distinctly. DMA results showed that, the storage modulus of PU composites are higher than that of pure PU, while consumption modulus are lower than that of pure PU, which indicates that the microphase separation of $\mathrm{PU}$ composites is improved. At the same time, DMA results reflect the information of interaction between the macromolecular chains and nanoparticles preferably.

\section{REFERENCES}

1. J.P. Sheth, D.B. Klinedinst, G.L. Wilkes, I. Yilgor and E. Yilgor, Polymer, 2005, 46, 7317-7322.

2. M. Furukawa, K. Kojio, S. Kugumiya, Y. Uchiba and Y. Mitsui, Macromol. Symp., 2008, 267, 9-15.

3. L. Bistricic, G. Baranovic, M. Leskovac and E. G. Bajsic, Eur. Polym. J., 2010, 46, 1975-1987.

4. J.T. Garrett, R.J. Xu, J. D. Cho and J. Runt, Polymer, 2003, 44, 2711-2719.

5. A. Woliñska-Grabczyk, B. Kaczmarczyk and A. Jankowski, Pol. J. Chem. Tech., 2008, 10, 53-56.

6. A. Rahimi, A. Mashak, Plast. Rubber. Compos., 2013, 42, 223-230.

7. G. Beniah, B.E. Uno, T. Lan, J. Jeon, W. H. Heath, K. A. Scheidt and J. M. Torkelson, Polymer, 2017, 110, 218217.

8. E.K. Leitsch, G. Beniah, K. Liu, T. Lan, W. H. Heath, K. A. Scheidt and J. M. Torkelson, ACS. Macro. Lett., 2016, 5, 424-429.

9. G. Beniah, X. Chen, B.E. Uno, K. Liu, E. K. Leitsch, J. Jeon, W. H. Heath, K. A. Scheidt and J. M. Torkelson. Macromolecules, 2017, 50, 3193-3203.

10. L. Wen, J.H. Zhang, T. Zhou, and A. M. Zhang, Vib. Spectrosc., 2016, 86, 160-172.

11. S. Koutsoumpis, K. N. Raftopoulos, M. Jancia, J. Pagacz, E. Hebda, C. M. Papadakis and K. Pielichowski, Macromolecules, 2016, 49, 6507- 6517.

12. A. Santiago, L. Martin, J. J. Iruin, M .J. FernándezBerridi, A. González and L. Irusta, Prog. Org. Coat., 2014, 77, 798-802.

13. Y. He, D. L. Xie, X. Y. Zhang, J. Mater. Sci., 2014, 49, 7339-7352.

14. M. Furukawa, Y. Mitsui, T. Fukumaru and K. Kojio, Polymer, 2005, 46, 10817-10822.

15. X. Wang, J. C. Xu, L. L. Li, Y. Liu, Y. Li and Q. Z. Dong, Polymer, 2016, 98, 311-319.

16. L. Rueda, B. F. d'Arlas, M. A. Corcuera and A. Eceiza, Polym. Degrad. Stabil., 2014, 108, 195-200.

17. S. L. Wu, T. J. Shi and L.Y. Zhang, High. Perform. Poly., 2015, 28, 453-465.

18. M. Maiti, A. K. Bhowmick, Polymer, 2006, 47, 61566166. 
19. Y. Camberlin, J. P. Pascault, J. Polym. Sci. Polym. Phys., 1986, 22, 1835-1844.

20. D. Wang, S. Fujinami, K. Nakajima, S. Inukai, H. Ueki, A. Magario, T. Noguchi, M. Endo and T. Nishi, Polymer, 2010, 51, 2455-2459.

21. D. Wang, K. Nakajima, S. Fujinami, Y. Shibasaki, J. Q. Wang and T. Nishi, Polymer, 2012, 53, 1960-1965.

22. N. Hao, J. N. Wu, J. Wan and Z. Y. Liu, Plast. Rubber Compos., 2017, 46, 346-354.

23. D. M. Wu, F. X. Qiu, H. P. Xu and D. Y. Yang, Plast. Rubber Compos., 2011, 40, 449-456.
24. P. V. Dhanaraj, T. Suthan and N.P. Rajesh, Curr. Appl. Phys., 2010, 10, 1349-1353.

25. L. Rueda, A. Saralegui, B. F. d'Arlas, Q. Zhou, L.A. Berglund, M.A. Corcuera, I. Mondragon and A. Eceiza, Carbohyd. Polym., 2013, 92, 751-757.

26. P. Schön, K. Bagdi, K. Molnár, P. Markus, B. Pukánszky and G. J. Vancso, Eur. Poly. J., 2011, 47, 692-698.

27. J. Yang, Y. L. Gao, J. H. Li, M. M. Ding, F. Chen, H. Tan and Qiang Fu, RSC. Adv., 2013, 3, 8291-8297.

28. H. Tan, M. Guo, R. N. Du, X. Y. Xie, J. H. Li, Y. P. Zhong and Q. Fu. Polymer, 2004, 45, 1647-1657.

29. L. M. Li and X. A. Huang, Polym. Eng. Sci., 2004, 30, 9-13. 
